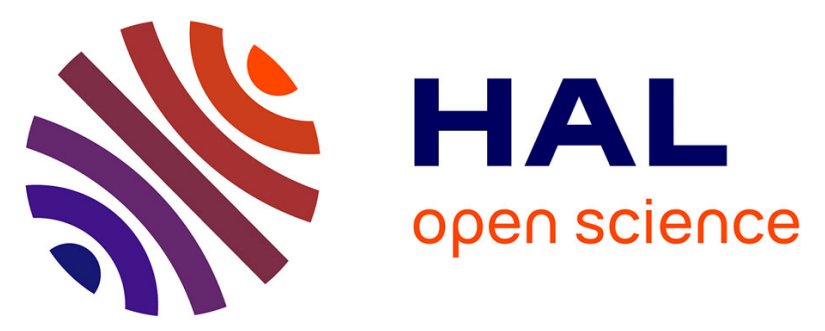

\title{
Obtention de plantes haploïdes par culture in vitro d'ovaires et d'ovules non fécondés de tournesol (Helianthus annuus L.)
}

\author{
Pascale Gelebart, Lean Han San, Mme Muriel Martin
}

\section{To cite this version:}

Pascale Gelebart, Lean Han San, Mme Muriel Martin. Obtention de plantes haploïdes par culture in vitro d'ovaires et d'ovules non fécondés de tournesol (Helianthus annuus L.). Agronomie, 1987, 7 (2), pp.81-86. hal-00884971

\section{HAL Id: hal-00884971 https://hal.science/hal-00884971}

Submitted on 1 Jan 1987

HAL is a multi-disciplinary open access archive for the deposit and dissemination of scientific research documents, whether they are published or not. The documents may come from teaching and research institutions in France or abroad, or from public or private research centers.
L'archive ouverte pluridisciplinaire $\mathbf{H A L}$, est destinée au dépôt et à la diffusion de documents scientifiques de niveau recherche, publiés ou non, émanant des établissements d'enseignement et de recherche français ou étrangers, des laboratoires publics ou privés. 


\title{
Obtention de plantes haploïdes par culture in vitro d'ovaires et d'ovules non fécondés de tour- nesol (Helianthus annuus L.)
}

\author{
Pascale GELEBART \& Lean Han SAN \\ avec la collaboration technique de Mme Muriel MARTIN
}

ADAR. Laboratoire d'Amélioration des Plantes. Bât. 360. Faculté des Sciences d'Orsay, 91405 Orsay Cedex

RÉSUMÉ

\begin{abstract}
Des plantes gynogénétiques ont été obtenues par culture in vitro d'ovaires et d'ovules de tournesol non fécondés, avec une fréquence moyenne de cinq plantes pour mille ovaires. Les embryons ou les cals gynogénétiques issus du sac embryonnaire ont été initiés sur un milieu d'induction comportant le milieu de base de Murashige \& Skoog complété avec 2 p.p.m. d'ANA et 10 p. 100 de saccharose. Les taux de régénération observés varient selon les génotypes, et les plantes régénérées représentent en moyenne 47 p. 100 des développements gynogénétiques obtenus. Le comptage chromosomique des méristèmes racinaires des plantes gynogénétiques a mis en évidence que la majorité des plantes obtenues est haplö̈de, et que le reste des plantes est diploïde ou mixoploïde $(2 n+n)$. Au cours de la croissance de la plante, le nombre de cellules haploïdes décroît et s'annule lors de la floraison. L'origine gamétophytique de ces plantes a été établie à l'aide d'études cytologiques effectuées en cours de culture sur des ovaires fécondés et non fécondés.
\end{abstract}

Mots clés additionnels : Gynogenèse, tournesol, haplö̈de, mixoploïde, culture in vitro.

Production of haploid plants of sunflower (Helianthus annuus L.) by in vitro culture of nonfertilized ovaries and ovules.

\begin{abstract}
Gynogenetic plants have been obtained by in vitro culture of unfertilized ovaries and ovules of sunflower, with an average rate of five plants per thousand cultured ovaries. Gynogenetic calluses or embryos from the embryo sac were initiated on a medium including Murashige \& Skoog basic medium, $10 \%$ sucrose and 2 p.p.m. NAA. Regeneration rates varied according to genotype. Regenerated plants represented about $47 \%$ of the gynogenetic embryos or calluses induced. Chromosome counts on the root meristems of gynogenetic plants showed that the majority were haploid, but that others were diploid or even mixoploid $(2 n+n)$. During plant growth, the haploid cell number decreased because of spontaneous doubling, and by flowering time, the plants had become diploid. The gametophytic origin of the plants was established by cytological studies on cultured unfertilized ovaries.
\end{abstract}

Additional key words : Gynogenesis, sunflower, haploid, mixoploid, in vitro culture.

\section{INTRODUCTION}

Le tournesol cultivé, Helianthus annuus L., est une espèce diploïde $2 \mathrm{n}=2 \mathrm{x}=34$ présentant une forte allogamie.

Les travaux de P. LECLERCQ sur la stérilité mâle nucléocytoplasmique (1969) ont résolu les problèmes de fiabilité des hybridations et permettent la création d'hybrides F1. Les premiers hybrides inscrits au catalogue ont montré d'emblée une vigueur et une productivité significativement augmentées par rapport à cel- les des variétés populations (comme Peredovik), ainsi qu'une meilleure homogénéité de maturation des capitules.

Cependant, l'obtention des lignées parentales demeure encore une des plus longues étapes du processus de création variétale, car le tournesol présente une forte autoincompatibilité dans la majeure partie des populations cultivées ainsi que dans les populations sauvages. Pour résoudre ce problème, on peut envisager l'haplodiploïdisation du tournesol par les techniques de culture in vitro en tant que moyen 
rapide et sûr d'obtention de plantes, puis de lignées homozygotes.

La gynogenèse a été choisie en raison des résultats déjà obtenus par cette technique sur de nombreuses espèces : l'orge (SAN NOEUM, 1976), le blé (ZHU et $a l ., 1981 b$ ), le riz (ASSELIN DE BEAUVILLE, 1980), le maïs (TRUONG-ANDRÉ \& DEMARLY, 1984), le tabac (ZHU \& WU, 1981), la betterave (HOSEMANS \& BoSSOUTROT, 1983) ainsi que sur des composées telles que le gerbera (SITBON, 1981), la laitue (SAN NOEUM, comm. pers.) et un croisement interspécifique entre H. annuus $\times$ H. tuberosus (ZHU et al., 1981a). Enfin la gynogenèse du tournesol a été réussie en Chine par CAI \& ZHOU en 1984, ainsi que par YANG et al. en 1985. Ces auteurs ont obtenus des plantules haploïdes. De plus, les résultats de SAN \& AHMADI (1982) ont montré que la gynogenèse induit une moindre variabilité par rapport à l'androgenèse, dans le cas de l'orge.

\section{MATÉRIEL ET MÉTHODES}

\section{A. Matériel végétal}

8 génotypes ont été utilisés :

- l'hybride F1 Mirasol et ses deux lignées parentales cm 303 A (mâle stérile) et rha 274 (restaureur) provenant des établissements Gavadour-Cargill,

- l'hybride F1 Clairsol et ses deux lignées parentales canp 3 (mâle stérile) et bza 1 (restaureur) provenant de l'I.N.R.A.,

- l'hybride F1 Boléro provenant de l'I.N.R.A.,

- un génotype R II, mâle stérile et hétérozygote pour le caractère anthocyane (rouge dominant) fourni par les établissements Rustica-Bio-Recherches.

Ces plantes ont été cultivées en plein champ en été, et en serre à Orsay $\left(23{ }^{\circ} \mathrm{C} \pm 5{ }^{\circ} \mathrm{C}, 16\right.$ heures de lumière, 10000 lux) en hiver.

\section{B. Détermination du stade de prélèvement des ovaires}

Une étude du développement du sac embryonnaire a été menée. Selon les génotypes, la maturité morphologique est acquise entre 12 et 72 heures avant l'ouverture du bouton floral.

Les ovaires sont prélevés avant la fécondation, pendant les derniers stades de la gamétogenèse femelle. Le sac embryonnaire est alors mature, et possède 2 synergides, 2 antipodes, l'oosphère et les deux noyaux polaires fusionnés en un seul gros noyau.

\section{Mise en culture des ovaires}

Aucun préconditionnement n'a été appliqué sur les inflorescences ou sur les ovaires. Les capitules sont récoltés à partir du stade décollement des pétales jusqu'au stade intermédiaire entre floraison pétales étalés et pleine floraison. Ils sont ensuite désinfectés pendant $10 \mathrm{mn}$ avec de l'hypochlorite de calcium $(70 \mathrm{~g} / 1)$, puis rincés une fois à l'eau stérile. Les mises en culture s'effectuent en conditions stériles sur un milieu d'induction nutritif synthétique solide. Les ovaires sont prélevés sur les fleurons 12 à 24 heures avant leur ouverture. Au cours de la culture, les ovules sont extraits de l'ovaire par simple dissection à l'œil nu des parois de l'ovaire. Ils sont alors replacés sur le même milieu de culture et dans la même position relative que les ovaires.

\section{Milieux de culture}

\section{Milieux d'induction}

Les milieux d'induction ont tous la même composition de base, et ne diffèrent que par les teneurs en sucre et les combinaisons hormonales.

Le pH est ajusté à 5,9 avec du KOH avant autoclavage.

Le milieu de base contient les macroéléments de Murashige \& SKOOG (1962) dilués de moitié, les microéléments de MURASHIGE \& SKOOG, les vitamines de Morel, du Fe EDTA à $10^{-4} \mathrm{M}$ par litre et de l'agar à $9 \mathrm{~g}$ par litre. Sept combinaisons différentes de substances de croissance et de saccharose, ajoutées au milieu de base ont été testées : cf. tableau 1 .

\section{TABLEAU 1}

Concentrations hormonales et teneur en sucre des milieux employés. Hormones and sugar concentrations of media. $($ KIN $=$ Kinétine $=$ kinetin $;$ SACCH $=$ Saccharose $=$ Sucrose $)$

\begin{tabular}{lcccccc}
\hline \multirow{4}{*}{ Milieux } & \multicolumn{6}{c}{ Substances de croissance et saccharose } \\
& 2,40 & AIA & ANA & KIN & BA & SACCH \\
& mg/l & mg/l & mg/l & mg/l & mg/l & mg/1 \\
\hline D 10 & 2 & - & - & - & - & 100 \\
D 6 & 2 & - & - & - & - & 60 \\
A 10 & - & - & 2 & - & - & 100 \\
A 6 & -- & - & 2 & - & - & 60 \\
K 10 & 2 & - & - & 1 & - & 100 \\
K 6 & 2 & - & - & 1 & - & 60 \\
Ge & - & 0,5 & - & 2 & 2 & 100 \\
\hline \hline
\end{tabular}

\section{Milieu de régénération}

Le milieu de régénération est composé du même milieu de base que les milieux d'induction. Toutefois il ne contient aucune substance de croissance, et seulement $20 \mathrm{~g} / 1$ de saccharose.

\section{E. Conditions de culture in vitro et d'obtention de plantes gynogénétiques}

Le conditionnement des ovaires mis en culture s'effectue à $29^{\circ} \mathrm{C}$ et à l'obscurité pendant 4 à 6 semaines. (Durant ce laps de temps, on désignera tout développement de type cal ou embryon, provenant du sac embryonnaire, sous le vocable de formation gynogénétique.)

Au terme de la période de conditionnement, les ovules sont disséqués afin de prélever les formations gynogénétiques qui sont ensuite placées sur le milieu de régénération afin de provoquer la différenciation des plantules. 


\section{F. Techniques cytologiques d'observation du dévelop- pement gynogénétique}

\section{Etudes histologiques}

Les ovaires ou les ovules sont fixés à l'alcool acétique (3 volumes d'alcool éthylique pour un volume d'acide acétique) pendant 24 heures. Le matériel peut alors être disséqué sous loupe binoculaire puis coloré au carmin acétique (carmin de Belling) et observé au microscope. Des observations cytologiques ont également été effectuées à partir de coupes sériées au microtome. Après déshydratation à l'alcool éthylique, puis à l'alcool buthylique, le matériel est inclus dans la paraffine. Des coupes fines $(10 \mu \mathrm{m})$ sont réalisées à l'aide d'un microtome, et, après déparaffinage, le matériel est coloré au bleu alcyan et à la safranine.

\section{Comptage chromosomique}

Les pointes de jeunes racines sont prélevées et placées dans l' $\alpha$ bromonaphtalène en solution saturée à 5 pour mille pendant une heure. Elles sont ensuite fixées pendant 24 heures dans l'alcool acétique puis colorées par le carmin de SNOw (1963) pendant 3 à 7 jours. Elles sont alors montées et écrasées dans une goutte de carmin de Belling. Les dénombrements chromosomiques s'effectuent sur les méristèmes racinaires, à raison de 50 métaphases minimum par plante.

\section{RÉSULTATS}

\section{A. Les milieux}

Dans un premier temps, les tests de milieu ont été réalisés avec un minimum de 500 ovaires mis en culture par milieu.

Des développements gynogénétiques des sacs embryonnaires ont été observés sur 4 milieux parmi les 7 employés. Il s'agit des milieux A6, A10, D6 et D10, contenant une seule auxine, soit du 2,4 D soit de l'ANA. Cependant, qualitativement, les meilleurs résultats ont été obtenus sur le milieu contenant $2 \mathrm{mg} / \mathrm{l}$ d'ANA et $100 \mathrm{~g} / 1$ de saccharose, car seuls les embryons obtenus sur ce milieu ont régénéré des plantes (tabl. 2) (fig. 1).

Ce milieu a été conservé ultérieurement.

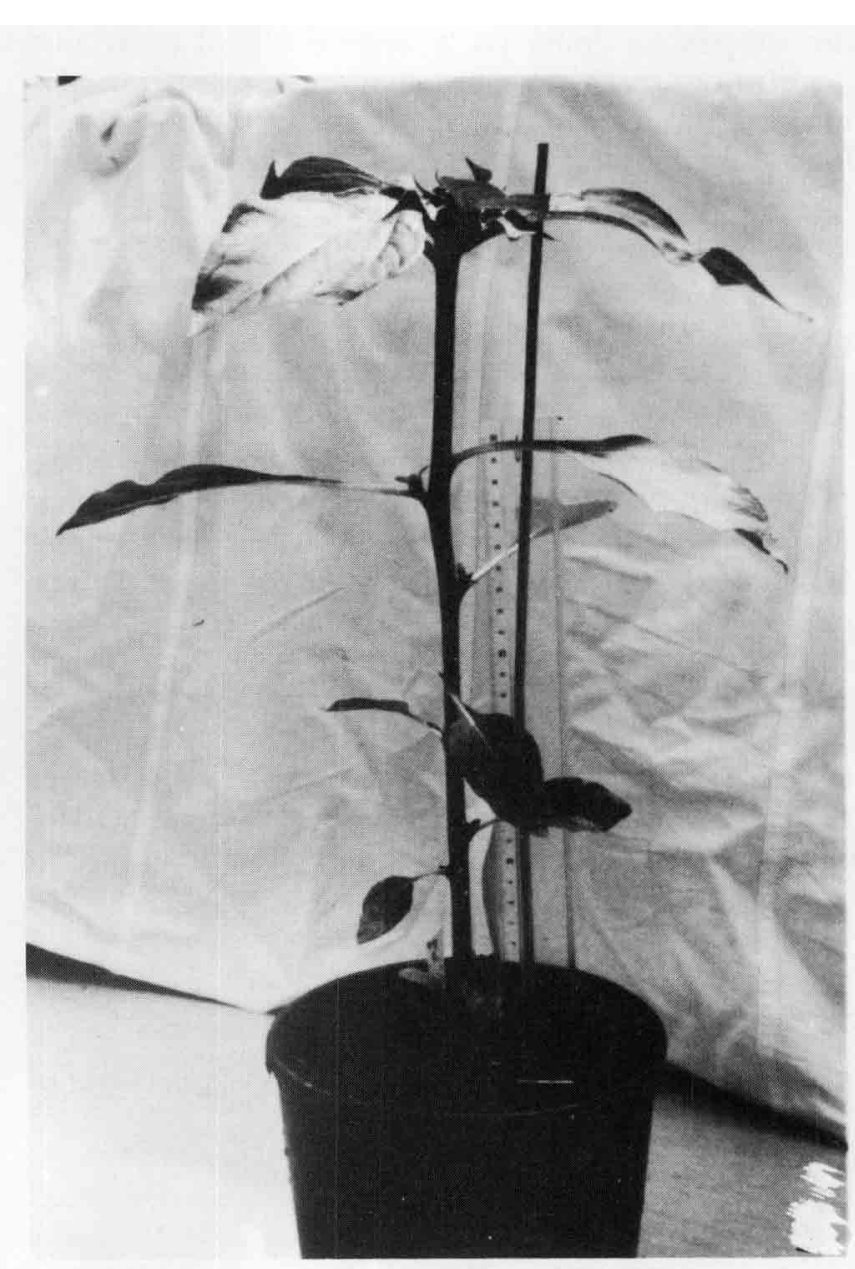

Figure 1

Plante haploide, en cours de doublement. Le capitule est visible. $\times 1 / 6$.

Haploid plant, during doubling. Inflorescence is visible.

TABLEAU 2

Taux d'induction gynogénétique et de régénération en fonction des différents génotypes.

O.C: Ovaires cultivés; $E:$ nombre d'embryons ; $(E / O) \times 100: \%$ d'embryon $; P:$ nombre de plantes $;(P / E) \times 100: \%$ de régénération $;$ $(P / O) \times 100:$ nombre de plantes pour 100 ovaires cultivés; niv. ploïdie : niveau de ploïdie des plantes; $d:$ diploïde ; $h:$ haploïde ; $m$ : mixoploìde.

Gynogenetic induction and regeneration rates according to genotypes.

O.C. : cultured ovaries $; E:$ embryo number $;(E / O) \times 100:$ embryo percentage $; P$ : plant number ; $(P / E) \times 100:$ regeneration percentage $;(P / O) \times 100:$ plants per 100 cultivated ovaries ; niv. ploidie : ploidy level; $d$ : diploid $; h:$ haploid ; $M:$ mixoploid.

\begin{tabular}{|c|c|c|c|c|c|c|c|}
\hline Génotypes & O.C. & $\mathrm{E}$ & $(\mathrm{E} / \mathrm{O}) \times 100$ & $\mathbf{P}$ & $(\mathrm{P} / \mathrm{E}) \times 100$ & $(\mathrm{P} / \mathrm{O}) \times 100$ & niv. ploïdie \\
\hline Clairsol & 1064 & 13 & 1,22 & 10 & 77 & 0,94 & $4 \mathrm{~d}, \quad 4 \mathrm{~h}, 2 \mathrm{~m}$ \\
\hline Mirasol & 774 & 10 & 1,29 & 4 & 40 & 0,52 & $3 \mathrm{~h}, 1 \mathrm{~m}$ \\
\hline Boléro & 1368 & 13 & 0,95 & 1 & 7 & 0,07 & $1 \mathrm{~h}$ \\
\hline Rha 274 & 820 & 13 & 1,59 & 8 & 61 & 0,98 & $1 \mathrm{~d}, 3 \mathrm{~h}, 4 \mathrm{~m}$ \\
\hline Bza 1 & 530 & 7 & 1,32 & 4 & 57 & 0,75 & $1 \mathrm{~d}, 2 \mathrm{~h}, 1 \mathrm{~m}$ \\
\hline $\mathrm{Cm} 303 \mathrm{~A}$ & 717 & 3 & 0,42 & 0 & 0 & 0 & - \\
\hline Canp 3 & 852 & 11 & 1,29 & 7 & 63 & 0,82 & $1 \mathrm{~d}, 5 \mathrm{~h}, 1 \mathrm{~m}$ \\
\hline R II & 437 & 8 & 1,83 & 3 & 37 & 0,69 & $1 \mathrm{~d}, 2 \mathrm{~h}$ \\
\hline TOTAL & 6562 & 78 & 1,19 & 37 & 47 & 0,56 & $8 \mathrm{~d}, 20 \mathrm{~h}, 9 \mathrm{~m}$ \\
\hline
\end{tabular}




\section{B. Nécessité d'une dissection intermédiaire et obten- tion de plantules}

Une émergence directe de plantules de l'ovaire comme celle décrite sur l'orge par SAN NOEUM (1976) n'a jamais été observée sur le tournesol.

Il est donc apparu nécessaire d'extraire les ovules des ovaires au cours de la culture afin d'éviter une dénutrition du sac embryonnaire. L'extraction des ovules avant le onzième jour de culture est indispensable à l'obtention d'embryons organisés ou de plantules. Les formations gynogénétiques apparaissent 4 à 6 semaines après la mise en culture des ovaires.

\section{Etude histologique du développement gynogénéti- que}

Le sac embryonnaire de tournesol est monosporique (NEWCOMB, 1973) ; par conséquent tous ses noyaux ont la même origine et portent le même génome. L'ovule portant ce sac embryonnaire est anatrope. Les études histologiques ont été menées sur 782 sacs embryonnaires, cultivés sur le milieu A 10, et provenant principalement des génotypes rha 274 et Mirasol.

Seuls 280 d'entre eux présentaient une activité mitotique. Il a été possible de répertorier les différentes cellules du sac embryonnaire présentant une activité chromatinienne (CHARRIER, 1985), cf. tableau 3.

\section{TABLEAU 3}

Répartition des activités cellulaires dans les sacs embryonnaires en culture.

Distribution of cellular activities in the cultivated embryo sacs.

\begin{tabular}{cccccc}
\hline \hline & \multicolumn{5}{c}{ Cellule du sac } \\
\cline { 2 - 6 } $\begin{array}{c}\text { Durée de } \\
\text { culture }\end{array}$ & $\begin{array}{c}\text { Oosphère } \\
\text { seul }\end{array}$ & $\begin{array}{c}\text { Antipodes } \\
\text { seules }\end{array}$ & $\begin{array}{c}\text { Oosphère } \\
+ \\
\text { antipodes }\end{array}$ & $\begin{array}{c}\text { Noyau } \\
\text { polaire }\end{array}$ & $\begin{array}{c}\text { Nombre } \\
\text { de sacs } \\
\text { observés }\end{array}$ \\
\hline 7 jours & 83 & 48 & 36 & 7 & 174 \\
10 jours & 32 & 7 & 4 & 4 & 61 \\
12 jours & 30 & 9 & 4 & 1 & 45 \\
\hline \hline
\end{tabular}

Au cours des deux premières semaines de culture, les tissus de l'ovule dégénèrent et se dessèchent, tandis que l'assise tapétale entourant le sac embryonnaire présente une activité mitotique intense. L'assise tapétale tout entière dégénère après 3 semaines de culture, qu'il y ait eu, ou pas, développement gynogénétique dans le sac embryonnaire.

Tous les embryons ou cals obtenus proviennent de l'extrémité micropylaire de l'ovule ; les formations gynogénétiques peuvent provenir de différentes parties du sac embryonnaire : celles de texture dense résultent du développement de l'oosphère ou du noyau polaire de fusion (fig. 2). Au contraire les développements observés au niveau des antipodes sont des amas cellulaires qui évoluent en cals friables inaptes à l'organogenèse.

Toutes les cellules du sac embryonnaire, à l'exception des synergides qui dégénèrent, sont concernées au

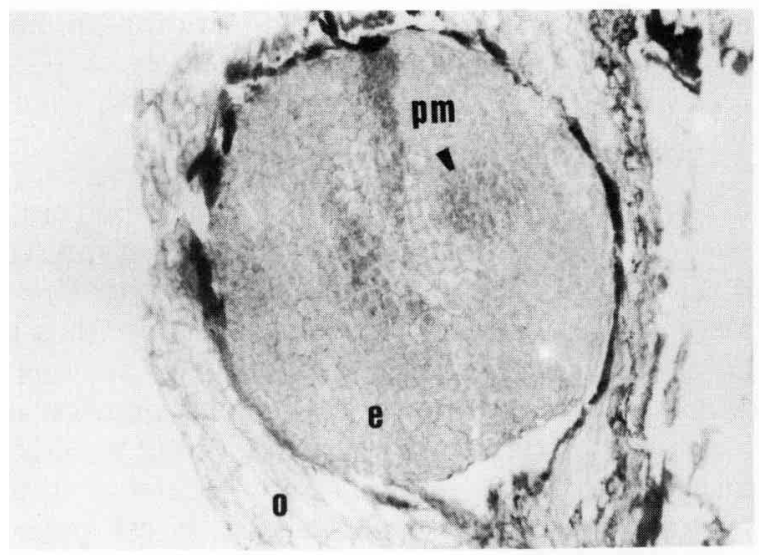

Figure 2

Embryon gynogénétique provenant de l'oosphère, au bout de 25 jours de culture. $\times 80$.

25-day-old gynogenetic embryo from egg cell.

$o:$ tissus de l'ovule/ovule tissues.

$e:$ tissus de l'embryon/embryo tissues.

pm : point méristématique/meristematic point.

même titre lors des premières étapes dans le cas d'un développement gynogénétique. Ainsi, à 7 jours de culture, on peut observer une activité nucléaire dans les antipodes, dans l'oosphère ainsi que dans la cellule centrale comportant le noyau polaire de fusion (fig. 3).

\section{Niveau de ploïdie des plantes régénérées}

Les racines examinées sont prélevées à différents stades de la croissance de la plante : à la sortie du tube, lors des premiers et deuxièmes repiquages (respectivement 15 jours et 6 semaines après le transfert

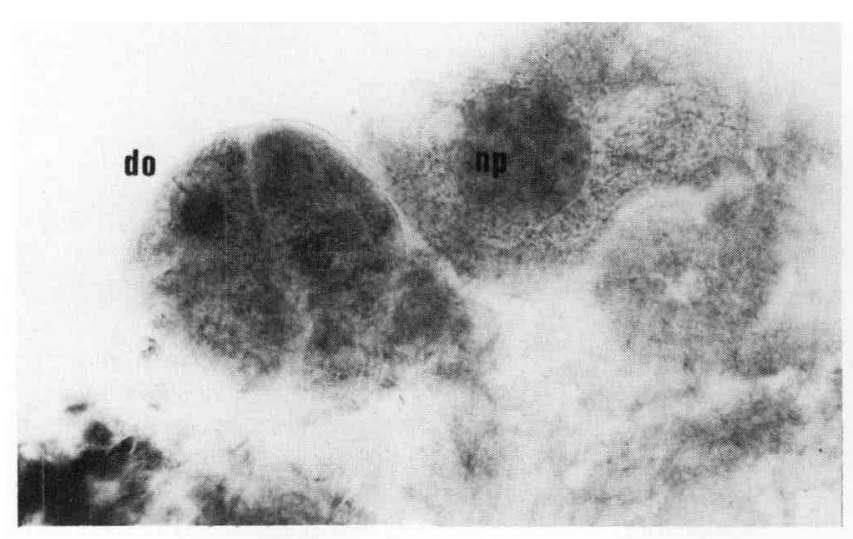

Figure 3

Initiation du développement gynogénétique dans un sac embryonnaire cultivé in vitro depuis 7 jours.

Initiation of gynogenetic development of in a 7-day-old cultured embryo sac. $\times 600$

do : divisions de l'oosphère - stade 4 cellules, dividing egg cell - 4-cell stage.

$n p$ : noyau polaire en dégénérescence, degenerating polar nucleus. 
en terre), puis à la floraison. Parmi les 37 plantes obtenues, 20 d'entre elles présentaient uniquement des métaphases haploïdes (fig. 4), et 8 des métaphases uniquement diploïdes (fig. 5).

L'éxämen des métaphases des 9 autres plantes obtenues a montré l'existence de cellules haploïdes et diploïdes au sein du même méristème racinaire, au cours du premier comptage chromosomique effectué. Ces plantes sont mixoploïdes $(n+2 n)$. Cependant, les pourcentages de métaphases haploïdes observés par comptage chromosomique dans les pointes de racines jeunes de ces plantes sont faibles ( 1 à 10 p. 100 des métaphases observées) comparés aux métaphases diploïdes. Au cours de la croissance des plantes, la fréquence de métaphases haploïdes décroît rapidement, et lorsque la floraison a lieu, toutes les métaphases observées sont diploïdes.

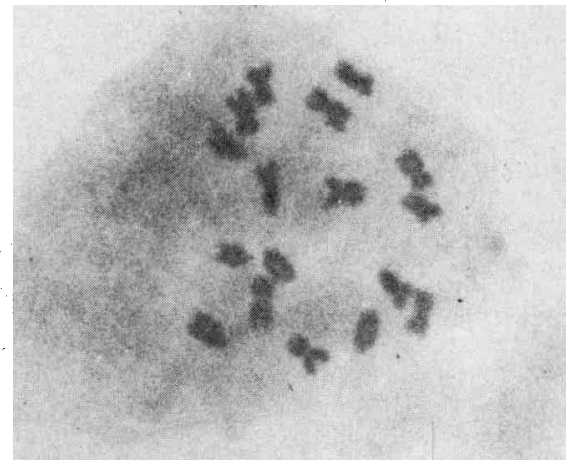

Figure 4

Métaphase haploïde $n=17 . \times 600$.

Haploid metaphase.

\section{DISCUSSION}

\section{A. Milieux}

Les milieux employés pour induire des développements gynogénétiques ont été choisis en fonction des résultats obtenus sur d'autres plantes.

Ainsi D10 et D6 emploient l'auxine utilisée par SAN NOEUM pour l'orge. A10 et A6 sont un aménagement du milieu employé pour la gynogenèse de laitue (SAN \& GELEBART, 1986).

La balance hormonale employée pour la gynogenèse du gerbera (SITBON, 1981) a été testée sur le tournesol par l'intermédiaire du milieu Ge. Enfin K6 et K10 ont été élaborés afin de tester une balance hormonale différente de celle du gerbera. Les milieux D10 et D6 ont permis d'induire des développements gynogénétiques, mais ces structures avortent et se nécrosent rapidement ; elles sont de type cal

Le milieu Ge a provoqué des proliférations cellulaires importantes des parois d'ovules et d'ovaires, mais aucun développement gynogénétique n'a été observé. Les milieux K6 et K10 ont induit des effets analogues à ceux du milieu Ge.

Seuls les milieux A10 et A6 ont permis d'obtenir des structures gynogénétiques embryonnaires, et le milieu A10 en a fourni davantage que A6.

\section{B. Histologie}

Les observations cytologiques du développement gynogénétique des sacs embryonnaires ont mis en évidence le même type d'évolution cellulaire que celle décrite par YAN et al. (1985), du moins dans les dix premiers jours de la culture.

Il est à noter que ces auteurs ont prélevé directement des ovules provenant de fleurons récoltés 1 à 4 jours avant l'anthèse, et les ont cultivés dans le milieu N6, additionné de $60 \mathrm{~g} / \mathrm{l}$ de saccharose et de $2 \mathrm{mg} / 1$ de MCPA (acide 2-méthyl-4-chloro phénoxyacétique), sous forme liquide.

Cependant, YANG et al. (1985) ont mis en évidence 2 types d'embryons au sein de l'ovule de tournesol :

- des embryons haploïdes, provenant du sac embryonnaire,

- des embryons somatiques provenant de l'assise tapétale entourant le sac embryonnaire, qui prolifère et évolue en tissu embryogène, dans les conditions de culture de ces auteurs.

Dans nos conditions expérimentales, la prolifération des cellules tapétales observée jusqu'à 3 semaines de culture n'a jamais conduit à un développement de type embryonnaire.

\section{Arguments en faveur de l'origine gynogénétique des plantes diploïdes}

Pour le génotype R II, il a été possible d'obtenir une plante verte diploïde et mâle stérile après mise en culture des ovaires d'un capitule ensaché pour prévenir les pollinisations éventuelles. Les caractéristiques de cette plante permettent de conclure à une origine gamétophytique. En effet, comme la plante mère était 
ensachée et que, par ailleurs, tous les autres génotypes présents à la serre en même temps que $\mathrm{R}$ II étaient restaureurs, on peut écarter l'hypothèse d'une origine zygotique pour cette plante. L'absence d'anthocyane permet également d'écarter l'éventualité d'une origine somatique, puisque, dans ce cas, la plante aurait été anthocyanée (sauf mutation éventuelle). Deux origines peuvent être envisagées pour les plantes comptées diploïdes dès le premier comptage.

En effet, l'embryon gynogénétique peut provenir soit du noyau polaire de fusion, soit de l'oosphère et, dans ce cas, un doublement spontané survient au cours des premières mitoses de son développement.

Deux hypothèses peuvent également être avancées concernant les plantes mixoploïdes : une origine mixte (noyau polaire + oosphère), ou bien un doublement progressif d'un embryon provenant de l'oosphère.

Sur les 37 plantes obtenues, 9 étaient mixoploïdes $(n+2 n), 20$ haploïdes et 8 diploïdes. Aucune différence de vigueur n'a été remarquée entre les mixoploïdes et les diploïdes.

\section{CONCLUSION}

Ces premiers résultats concernant la culture in vitro d'ovaires et d'ovules de tournesol non fécondés sont très encourageants pour la production de lignées haploïdes doublées. La gynogenèse pourrait assurer une production d'homozygotes en une seule génération et permettre ainsi l'examen des recombinaisons favorables apparues à l'issue d'une hybridation entre 2 lignées par haplodiploïdisation de l'hybride F1. Elle permettrait également de terminer rapidement la fixation de lignées en F5 ou en F6.

L'application de la gynogenèse permettrait donc de réduire les délais de création variétale, bien que les taux d'induction et d'obtention de plantes restent à améliorer.

Reçu le 24 janvier 1986. Accepté le 28 octobre 1986.

\section{RÉFÉRENCES BIBLIOGRAPHIQUES}

Asselin de Beauville M., 1980. Obtention d'haploïdes in vitro à partir d'ovaires non fécondés de riz, Oryza sativa L. C. R. Acad. Sc. (Paris), 290 D, 489-492.

Cai D., Zhou C., 1984. In vitro induction of haploid embryoids and plantlets from unpollinated young florets and ovules of Helianthus annuus L. Kexue Tongbao, 29 (5), 680-682.

Charrier P., 1985. Etude cytologique du développement gynogénétique chez le tournesol (Helianthus annuus L.). D.E.A. de Génétique quantitative et appliquée.

Hosemans D., Bossoutrot D., 1983. Induction of haploid plants from in vitro culture of unpollinated beet ovules (Beta vulgaris L.). Z. Pflanzenzüchtg., 91, 74-77.

Leclercq P., 1969. Une stérilité mâle cytoplasmique chez le tournesol. Ann. Amélior. Plantes, 18 (3), 99-106.

Murashige T., Skoog F., 1962. A revised medium for rapid growth and bio-assays with tobacco tissue culture. Physiol. Plant., 15, 473497.

Newcomb W., 1973. The development of the embryo sac of Helianthus annuus L. before fertilization. Can. J. Bot., 51, 5, 863-878.

San Noeum L. H., 1976. Haploïdes d'Hordeum vulgare L. par culture in vitro d'ovaires non fécondés. Ann. Amélior. Plantes, 26 (4), 751-754.

San L. H., Ahmadi N., 1982. Variability of doubled haploids from in vitro androgenesis and gynogenesis in Hordeum vulgare $\mathrm{L}$. in «Variability in plants regenerated from tissue culture ». EARLE E. D. et Demarly Y. (eds), Praeger Press, New York, 273-283.

San L. H., Gelebart P., 1986. Production of gynogenetic haploids, 305-322, Ch. 15, in Vasil I. K., Cell Culture and Somatic Cell Genetics of Plants, vol. 3. Academic Press (sous presse).
Sitbon M., 1981. Production of haploid Gerbera jamesonii plants by in vitro culture of unfertilized ovules. Agronomie, 1 (9), 807-812.

Snow R., 1963. Alcoholic hydrochloric acid-carmine as a stain for chromosomes in squash preparations. Stain Technol., 38, 9-13.

Truong-André I., Demarly Y., 1984. Obtaining plants by in vitro culture of unfertilized maize ovaries (Zea mays L.) and preliminary studies on the progeny of a gynogenetic plant. Z. Pflanzenzüchtg., 92, 309-320

Yan H., Wu Y., Chen X. M., Wei Z. Y., Zhou C., Yang H. Y., 1985. Microscopical observations on the embryoid formation in cultured unfertilized ovules of Helianthus annuus L. Acta Bot. Sin., 27 (1), 13-18

Yang H. Y., Zhou C., Cai D., Yan H., Wu Y., Chen X. M., 1985. In vitro culture of unfertilized ovules in Helianthus annuus L., 182 191. In HU H. \& Y ANG H. Y., Haploids of Higher Plants in vitro. China Academic Publishers, Beijing, Springer-Verlag.

Zhu Z., Wu H., 1981. Induction of haploid plantlets from unpollinated ovaries on Nicotiana tabacum L. cultured in vitro. Acta Genet. Sin., 8, 63-65.

Zhu Z., Wu H., An Q., Liu Z., 1981a. Haploid plantlets regenerated from unpollinated ovaries of (Helianthus tuberosus L. $\times$ Helianthus annuus L.) F1. Ann. Rep. Inst. Genet., Acad. Sin., 125.

Zhu Z., Whu H., An Q., Liu Z., 1981b. Induction of haploid plantlets from unpollinated ovaries of Triticum aestivum L. cultured in vitro. Acta Genet. Sin., 8, 386-390. 